\title{
Physical modeling of land subsidence due to underground cavity and its monitoring by electrical resistivity survey in geotechnical centrifuge
}

\author{
Cho Hyung Ik ${ }^{\text {i) }}$, Bang Eun Seok ${ }^{\text {ii) }}$, Yi Myeong Jong ${ }^{\text {iii) }}$ and Kim Dong Soo ${ }^{\text {iv) }}$
}

\begin{abstract}
i) Graduate Student, Department of Civil and Environmental Engineering, KAIST, 291 Daehak-ro, Daejeon 305-701, Korea. ii) Senior Researcher, Exploration Geophysics Group, Korea Institute of Geoscience and Mineral Resources, Gwahang-no 124, Daejeon 305-350, Korea. iii) Senior Researcher, Exploration Geophysics Group, Korea Institute of Geoscience and Mineral Resources, Gwahang-no 124, Daejeon 305-350, Korea.

iv) Professor, Department of Civil and Environmental Engineering, KAIST, 9-13, 291 Daehak-ro, Daejeon 305-701, Korea.
\end{abstract}

\begin{abstract}
Hazardous sinkholes started to emerge as a new problem that threatens the safety of the people in Korea. In this study, sinkhole simulation and monitoring in centrifuge test were designed to make environment for related research. Electrical resistivity monitoring system was built in centrifuge facility and $1 \mathrm{~g}$ preliminary test was performed using ice blocks in order to ensure the simulation of underground cavities in centrifuge model. Subsequently, $20 \mathrm{~g}$ centrifuge test was performed simulating two types of underground cavities such as existing cavity and water leakage from sewage pipeline. After reaching target centrifugal g-level, groundwater was injected from the base of model box to simulate the groundwater level change. Electrical resistivity survey was conducted continuously to monitor the underground anomalies. The electrical resistivity results from the centrifuge test corresponds well to expected process of sinkhole generation by showing the definite resistivity difference between underground cavities and adjacent soils. From the underground cavity simulation in centrifuge, it is noticed that electrical resistivity survey could monitor the process of underground cavity generation effectively, and developed monitoring system can be applied to further the parametric studies in sinkhole research.
\end{abstract}

Keywords: electrical resistivity survey, centrifuge test, monitoring, land subsidence

\section{INTRODUCTION}

Hazardous sinkholes started to emerge as a new problem that threatens the safety of the people in Korea (Fig. 1). Since 2010, large sinkholes greater than $2 \mathrm{~m} \mathrm{x}$ $2 \mathrm{~m}$ by width and length have occurred in more than 14 locations in Seoul (Lee \& Kang 2014). In order to proactively prepare for the disasters caused by the sinkholes, research about generating mechanism and field monitoring are very important.

Comprehensive research related to sinkhole generation was carried out for susceptible soil material, deposit, and structures affecting groundwater flow. Most laboratory studies were conducted by $1 \mathrm{~g}$ model tests using 2-dimensional model box which has transparent front wall to monitor soil's deformation by image processing technique. However, those model tests have certain limitations due to narrow and limited space for specimen preparation. Because, sinkhole is generally caused by loss of soil resistance, any mechanism that can affect particle structure (or stress-state) such as the arching effect caused by wall friction can affect the major particle deformation behavior. Furthermore, the limited space makes applications of geophysical exploration techniques to be difficult due to isolated boundary conditions, even though those techniques are powerful to visualize the subsurface and are widely used in the field tests. It is also difficult to simulate the actual soil behavior in small-scale $1 \mathrm{~g}$ model test because of the unique characteristics of soil (i.e., particulate media) which is governed by the confining stress.

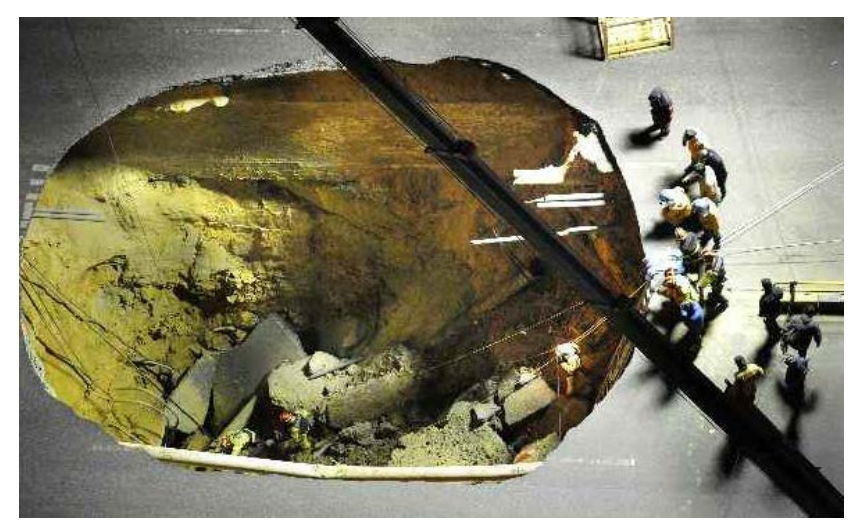

Fig. 1. A sinkhole due to subway construction in Korea.

In case of field study for sinkhole generation and monitoring, electrical resistivity survey was generally 
adopted. However, it demands lot of time and effort to find out optimal arrangement of electrodes and distance between them, because of the uncertainties regarding electric parameters even in the sinkhole susceptible area.

Geotechnical centrifuge modeling can be an alternative tool for the sinkhole research. Threedimensional centrifuge test with electrical resistivity monitoring system can solve the above mentioned problems and can be applied for parametric study with respect to the soil materials, deposit, and so on. Prior to performing those parametric studies, development and verification of electrical resistivity monitoring system in centrifuge facility have to be carried out. In this study, commercial electrical resistivity monitoring system was installed in centrifuge facility and land subsidence generated by two different cases was simulated in the centrifuge model and the 2-D electrical resistivity images were obtained during the tests to verify the applicability of the developed system.

\section{DEVELOPMENT OF ELECTRICAL RESISTIVITY SURVEY SYSTEM IN CENTRIFUGE}

A centrifuge facility with a $5 \mathrm{~m}$ platform radius and weighing 240 g-tons was used for this study as presented in Fig. 2 (Kim et al. 2013).

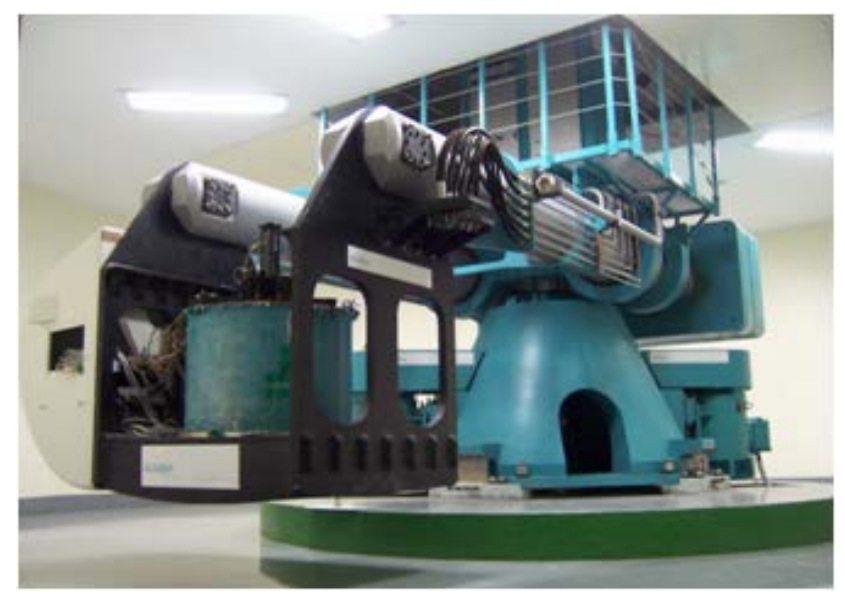

Fig. 2. Centrifuge facility.

For using the electrical resistivity survey system in the centrifuge facility, the SuperSting R8 produced by AGI Co. was utilized with its remote monitoring system (Cho et al. 2014). In order to remotely operate the system during the centrifuge in-flight test, it is required to connect the electrical resistivity survey system (i.e., SuperSting R8) with the server computer which is installed on the center axis of the centrifuge using the interface box. The necessary facilities were installed on the center axis of rotation where centrifugal acceleration is minimum as shown in Fig. 3. The developed electrical resistivity monitoring system can be controlled by the user PC in the remote control room. Therefore, it is possible to establish communication between the control room and the centrifuge chamber during the test.

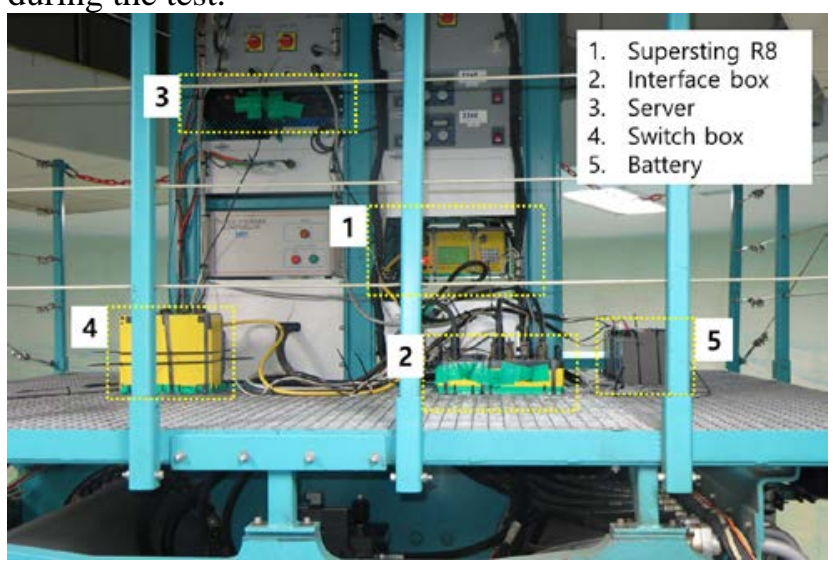

Fig. 3. Electrical resistivity measurement system installed on the central axis of centrifuge rotation.

\section{1G PRELIMINARY TEST}

In order to ensure land subsidence caused by underground cavities during the centrifuge test, a preliminary test was conducted at the 1g-level. The model box utilized in the test was made of aluminum having size of $70 \mathrm{~cm} \times 1100 \mathrm{~cm} \times 70 \mathrm{~cm}$ (width by length by height) and model ground of $40 \mathrm{~cm}$ height was constructed in the box using soil mixture having basic physical properties as presented in Table 1 . Two ice blocks were buried within model ground to simulate existing underground cavities. The ice block's size was $5 \mathrm{~cm} \times 5 \mathrm{~cm} \times 10 \mathrm{~cm}$ (by width by length by height). The first ice block was placed at a depth of $10 \mathrm{~cm}$ below ground surface and in 1/3 in length of model box whereas the second ice block was buried at a depth of $5 \mathrm{~cm}$ and in 2/3 in length of model box.

A total of 26 electrodes with $4 \mathrm{~cm}$ distance between each electrode were installed in a line on the surface directly above the ice block for the electrical resistivity measurement. The type of the electrode array was Dipole-Dipole array which is the most commonly used array method. To simulate the underground water level change, ground water was injected from the bottom of the box. Electrical resistivity monitoring was conducted continuously to monitor the underground anomalies immediately after the model preparation to the model ground subsidence. As an inversion program for apparent resistivity, DCPro (Kim 2012) was adopted.

Table 1. Basic physical properties of soil material.

\begin{tabular}{lllll}
\hline Material & USCS & PI & Gs & $\begin{array}{l}\text { Hydraulic conductivity } \\
(\mathrm{cm} / \mathrm{sec})\end{array}$ \\
\hline Silica sand & SP & NP & 2.63 & - \\
\hline Kaolinite & CH & 42 & 2.67 & $12 \sim 146 \times 10^{-8}$ \\
\hline Mixture & $\begin{array}{l}\text { Silica sand }\left(90.9 \%^{*}\right)+ \\
\text { Kaolinite }(9.1 \% *)\end{array}$ & $3 \times 10^{-5}$ \\
\hline
\end{tabular}

* ratio of weight 


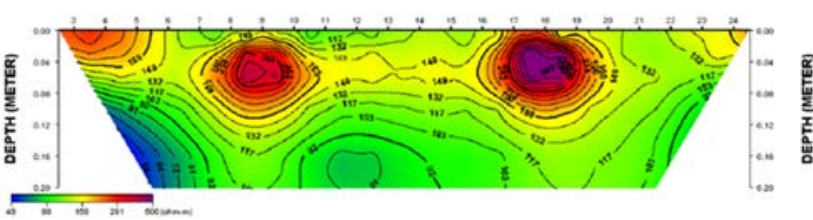

(a) After ice melting

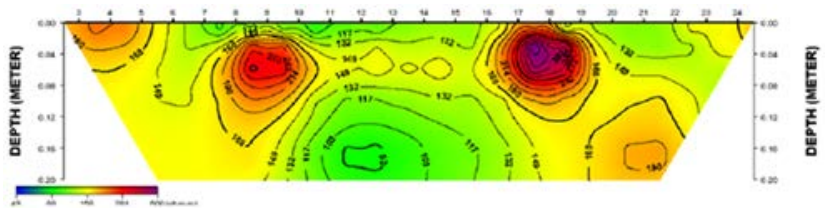

(b) During groundwater rising

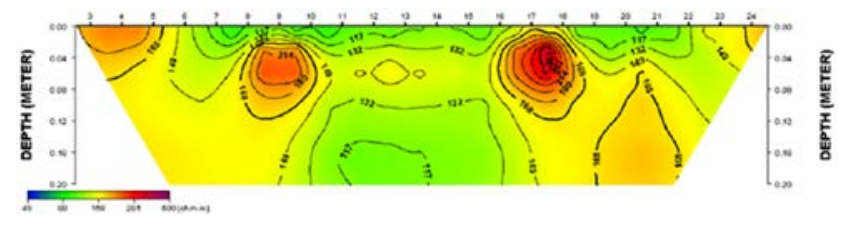

(c) Just before ground subsidence

Fig. 4. Electrical resistivity images of $1 \mathrm{~g}$ test.

Fig. 4 shows electrical resistivity results from the $1 \mathrm{~g}$ test. A definite electrical resistivity difference and a clear contrast between two cavities and adjacent soil were observed as seen in the figures. It seems that the underground cavity having high electrical resistivity was generated by ice melting. The contrast got lighter as increasing the groundwater level. As groundwater level increases the electrical resistivity within cavities decreases because the groundwater fills the cavities. In addition, position of the anomalies appeared depending on the position of the ice block installed as expected. The anomaly on the right side emerged $5 \mathrm{~cm}$ higher than that on the left side. The land subsidence occurred at the end of the $1 \mathrm{~g}$ test and the top view at the end of the test is shown in Fig. 5.

Through the 1g preliminary test, the feasibility of ice block for underground cavity simulation was verified.

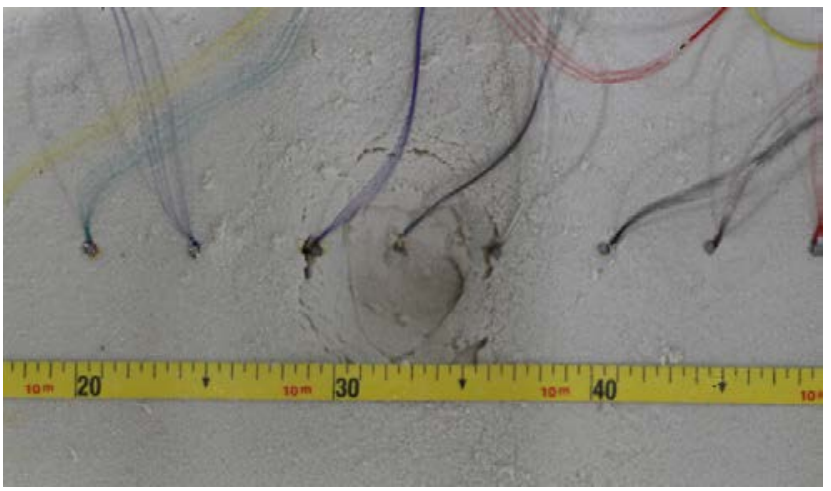

Fig. 5. Sinkhole generation during $1 \mathrm{~g}$ test.

\section{20G CENTRIFUGE TEST}

Possible causes of sinkhole generation are excessive use of groundwater, disturbance of groundwater flow due to urbanization, and water leakage in water supply and sewage system. In order to simulate the two different type of cavities by centrifuge modeling, a cavity caused by water leakage in sewage system and an existing cavity were selected.

Fig. 6 shows the schematic diagram of centrifuge modeling. The ice block on the left side was designed to simulate an existing cavity as mentioned in the $1 \mathrm{~g}$ test and on the right side PVC pipe simulated the damaged sewage pipe. The edge of sewage pipe was vertically installed to avoid its effect on the electrical resistivity measurements, although, the sewage pipeline is generally parallel to the ground surface. The PVC pipe, thus, acts as a channel for transportation of collapsed soil into sewage pipe. The tip opening of PVC pipe was $3 \mathrm{~cm}$.

The same model box used in the $1 \mathrm{~g}$ model test was utilized in the centrifuge test. The model ground consisted of 4 layers. The top layer was residual soil of $23 \mathrm{~cm}$ thickness. The soil properties are tabulated in Table 2. The arrangement of electrodes was identical with 1g preliminary test, however, the distance between the electrodes was $5 \mathrm{~cm}$ in this test. The centrifuge test was performed in 20g-level. A $3 \mathrm{~cm}$ opening of the PVC pipe, simulates a defect of $0.6 \mathrm{~m}$ size on the sewage pipe based on the scaling laws. After reaching $20 \mathrm{~g}$ centrifugal acceleration, groundwater was injected from the bottom of model box to simulate stress release and corresponding soil collapse into PVC pipe by the groundwater level change. Electrical resistivity monitoring was continuously carried out before and after cavity generation during the centrifuge in-flight state.

Table 2. Physical properties of soil used in 20g centrifuge test.

\begin{tabular}{lllll}
\hline USCS & $\mathrm{Cu}$ & $\begin{array}{l}\mathrm{D}_{50} \\
(\mathrm{~mm})\end{array}$ & Gs & $\begin{array}{l}\text { Hydraulic conductivity } \\
(\mathrm{cm} / \mathrm{sec})\end{array}$ \\
\hline $\mathrm{SM}$ & 2.11 & 0.08 & 2.67 & $4.74 \times 10^{-5}$ \\
\hline
\end{tabular}

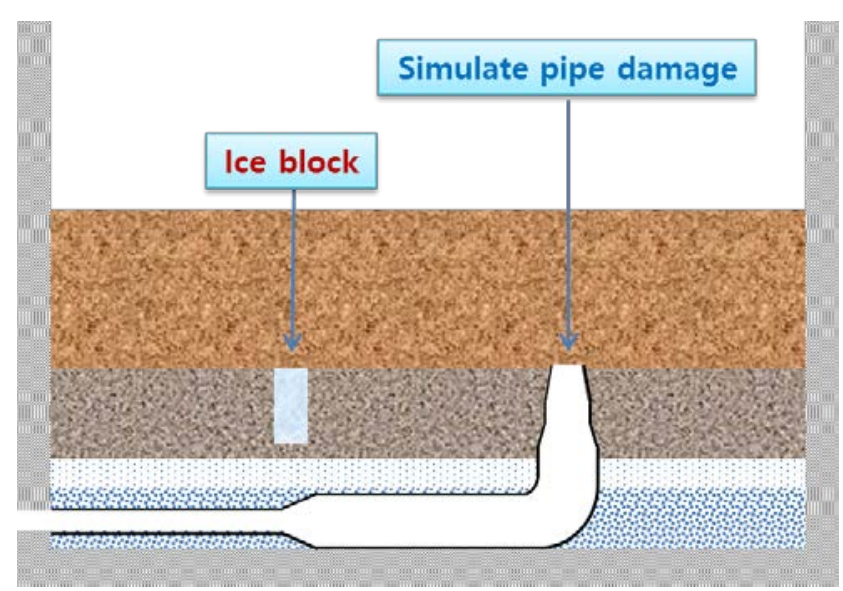

Fig. 6. Model configuration for $20 \mathrm{~g}$ centrifuge test. 

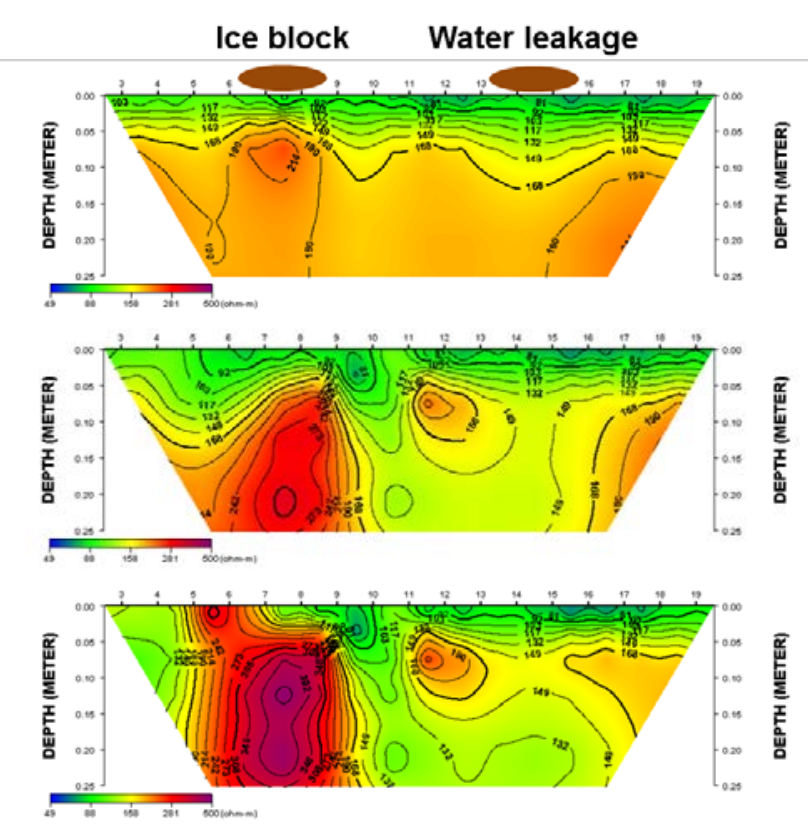

Fig. 7. Electrical resistivity images during centrifuge test.

Fig. 7 presents electrical resistivity images from the centrifuge test. The images cover up to depth of $25 \mathrm{~cm}$. The contrast in electrical resistivity is getting clear especially on the left side as groundwater increases. This means that the underground cavity generation resulted from the stress loosening and subsequent soil collapse into the lower subsurface due to increasing groundwater level. However, this phenomena cannot be observed on the right side. Fig. 7 show the phases the before sinkhole generation. At the end of the centrifuge test, the sinkholes were generated as shown in Fig. 8.

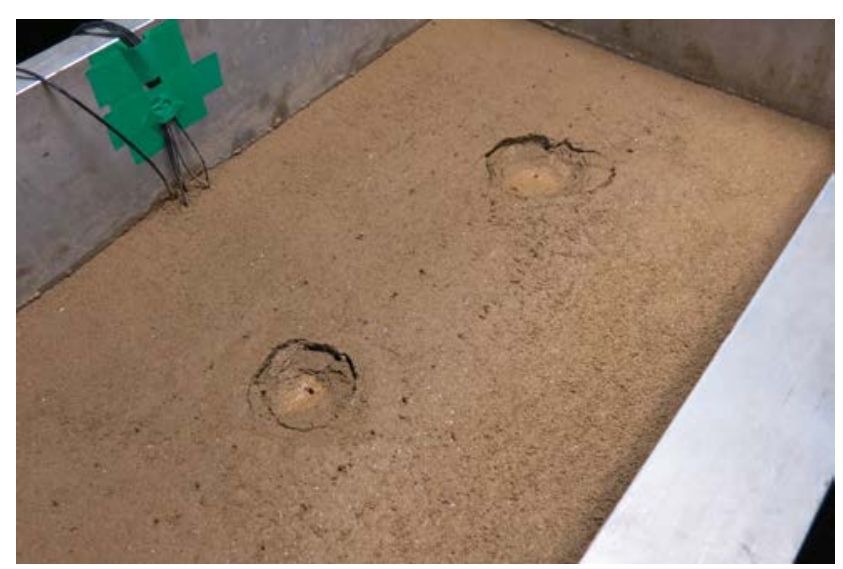

Fig. 8. Model ground subsidence after centrifuge test.

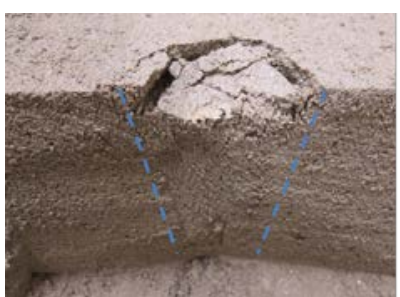

(a) Ice block

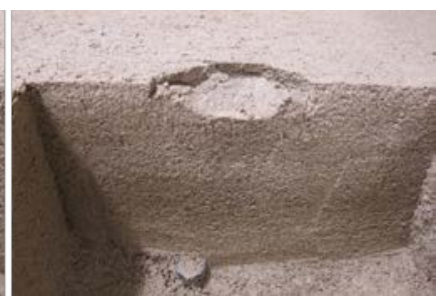

(b) water leakage

Fig. 9. Cutoff images of subsurface

After centrifuge test, subsurface below sinkholes was cut as shown in Fig. 9. Apparent wedge failure was observed in the ice block side whereas there was no failure plane observed in water leakage side.

\section{CONCLUSIONS}

The electrical resistivity monitoring system was built in the centrifuge facility to adopt the electrical resistivity survey technology in sinkhole simulation. To ensure the underground cavity simulation in centrifuge model, $1 \mathrm{~g}$ preliminary test was carried out. Subsequently, 20g centrifuge test was performed simulating two types of underground cavities. From the underground cavity simulation in centrifuge, it is noticed that electrical resistivity survey could monitor the process of underground cavity generation effectively. It is expected that the developed monitoring system can be applied to further the parametric studies in sinkhole research.

\section{ACKNOWLEDGEMENTS}

This study was supported by 'Development of 4-D Fusion Geophysical Exploration Technology' funded by Korea Institute of Geoscience and Mineral Resources.

\section{REFERENCES}

1) Cho, H. I., Bang, E. S., Yi, M. J., Choo, Y. W. and Kim, D. S. (2014): Development of Electrical Resistivity Survey System for Geotechnical Centrifuge Modeling, Journal of The Korean Geotechnical Society, 30(10), 19-31 (in Korean).

2) Kim, D. S., Kim, N. R., Choo, Y. W. and Cho, G. C. (2013): A newly developed state-of-the-art geotechnical centrifuge in Korea, KSCE Journal of Civil Engineering, 17(1), 77-84.

3) Kim, J. H. (2012): DC pro Manual, Kora Institute of Geoscience and Mineral Resources (KIGAM).

4) Lee, K. Y. and Kang, S. J. (2014): Sinkhole; causes and countermeasures, Issue \& Analysis, 156, 1-23 (in Korean). 